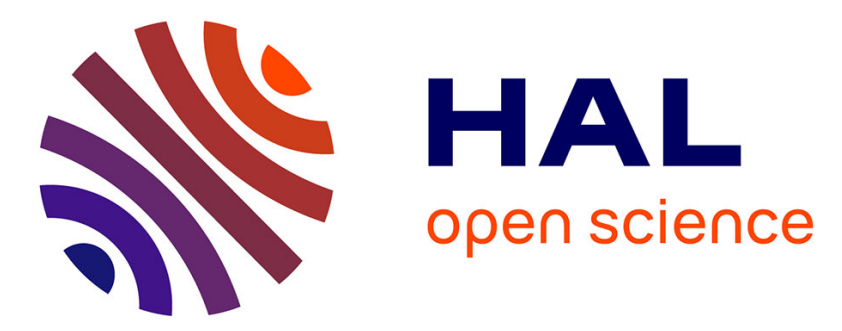

\title{
A mason type analysis of cylindrical ultrasonic micromotors
}

Marc Budinger, Jean-François Rouchon, Bertrand Nogarède

\section{To cite this version:}

Marc Budinger, Jean-François Rouchon, Bertrand Nogarède. A mason type analysis of cylindrical ultrasonic micromotors. European Physical Journal: Applied Physics, 2004, 25 (1), pp.57 - 65. 10.1051/epjap:2003085 . hal-01861787

\section{HAL Id: hal-01861787 https://hal.science/hal-01861787}

Submitted on 25 Aug 2018

HAL is a multi-disciplinary open access archive for the deposit and dissemination of scientific research documents, whether they are published or not. The documents may come from teaching and research institutions in France or abroad, or from public or private research centers.
L'archive ouverte pluridisciplinaire $\mathbf{H A L}$, est destinée au dépôt et à la diffusion de documents scientifiques de niveau recherche, publiés ou non, émanant des établissements d'enseignement et de recherche français ou étrangers, des laboratoires publics ou privés. 


\title{
A MASON TYPE ANALYSIS OF CYLINDRICAL ULTRASONIC MICROMOTORS
}

\author{
M. Budinger, J-F. Rouchon and B. Nogarede \\ Laboratoire d'Electrotechnique et d'Electronique Industrielle, Groupe « Machines et Mécanismes Electroactifs - EM² », \\ LEEI, INPT-ENSEEIHT, 31000 TOULOUSE, FRANCE \\ e-mail : name@leei.enseeiht.fr \\ Phone : (33) 0561588208 Fax: (33) 0561638875
}

\begin{abstract}
This paper deals with the global analytical modelling of cylindrical piezoelectric micromotors. The modelling, based on an equivalent electric circuit, is established by using geometrical and electromechanical parameters for the different parts of the motor. The motor stator is represented here in a form very similar to a traditional Mason circuit. The differences occur in the particular configurations of movement, namely flexural instead of longitudinal vibrations. In the equivalent circuits, contact between rotor and stator is represented by voltages which are functions of vibratory speed. Useful results for design can be obtained such as torque/speed curve, no load admittance, supply voltage, stress and amplitude of vibrations. This modelling is simple to implement and would also lend itself to optimisation by analytical methods because of the relatively small amount of computation required.
\end{abstract}




\title{
A MASON TYPE ANALYSIS OF CYLINDRICAL ULTRASONIC MICROMOTORS
}

\author{
M. Budinger, J-F. Rouchon and B. Nogarede \\ Laboratoire d'Electrotechnique et d'Electronique Industrielle, Groupe « Machines et Mécanismes Electroactifs - \\ $\mathrm{EM}^{2} \gg$, LEEI, INPT-ENSEEIHT, 31000 TOULOUSE, FRANCE \\ e-mail : name@leei.enseeiht.fr
}

\begin{abstract}
This paper deals with the analytical modelling of piezoelectric cylindrical micromotors [1] and supplements kinematics analysis done by [2]. The modelling, based on an equivalent electric circuit, is established by using geometrical and electromechanical parameters for the different parts of the motor. It gives electromechanical characteristics and other useful values for motor design.
\end{abstract}

Keywords : ultrasonic micromotor, TWUM, analytical modelling, equivalent circuit.

\section{Introduction}

Piezoelectric actuators have many well-known advantages compared with other technologies. They provide a high torque-mass ratio, they can lock when the supply is switched off and they ensure increased comfort of use [3][4]. Cylindrical type ultrasonic motors have interesting characteristics for a good electromechanical energy conversion and have a very simple structure which is adapted to millimetric sizes. However there is litte in literature which deals with modelling and theoretical analysis. The objective of this paper is to supplements the kinematics analysis done by [2]. The analytical modelling presented here is based on electric equivalent circuit and gives a global but simple model of the motor. 


\section{Modeling of the rotating-mode motor stator}

Cylindrical ultrasonic micromotor has a cylindrical stator and two rotors. The stator consists of a titanium tube, a layer of PZT thin film and electrodes as shown in fig. $\mathrm{n}^{\circ} 1$. The poling direction of the PZT film is in the thickness direction. The fundamental bending vibration is generated by the piezoelectric length-extension effect.

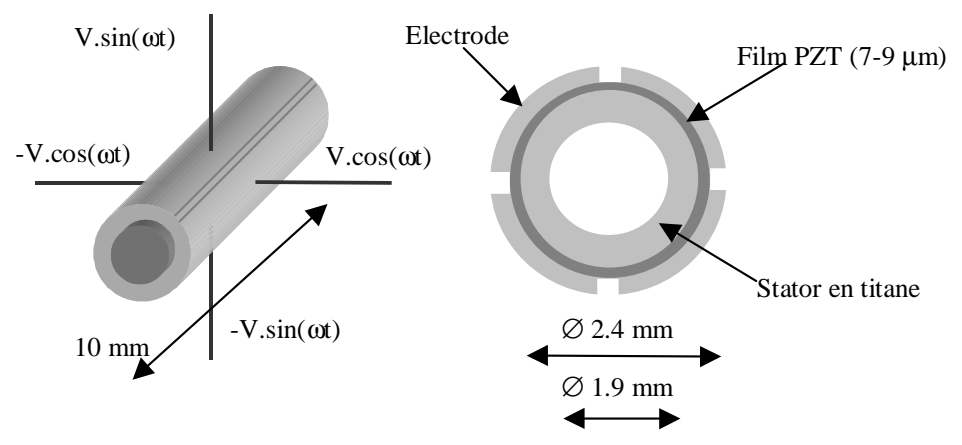

Figure $n^{\circ} 1:$ The structure of the stator transducer [1]

The stator of the rotating-mode motor presents a structure which resembles a Langevin type transducer. The difference comes from the level of the excited modes; modes of flexion for rotating-mode motor and longitudinal vibration modes for the Langevin type transducer.

\section{Equivalent electric circuit modeling of Langevin type actuator}

The Langevin type transducer is modeled in a classic way with Mason equivalent electric circuits [5]. From the transducer geometry, they make it possible to get a relatively precise model of the electro-mechanical conversion based on an analogy between longitudinal vibratory speed and current (the counterpart of effort in one section is then voltage). According to this approach, a non piezoelectric rod in traction/compression can be modeled by the equivalent circuit of Fig. $\mathrm{n}^{\circ} 2$ where voltage $F$ and current $\dot{U}$ represent respectively the effort and speed at the extremities of the rod. A transformer which expresses the electromechanical energy conversion is added to the circuit for a piezoelectric ceramic. 

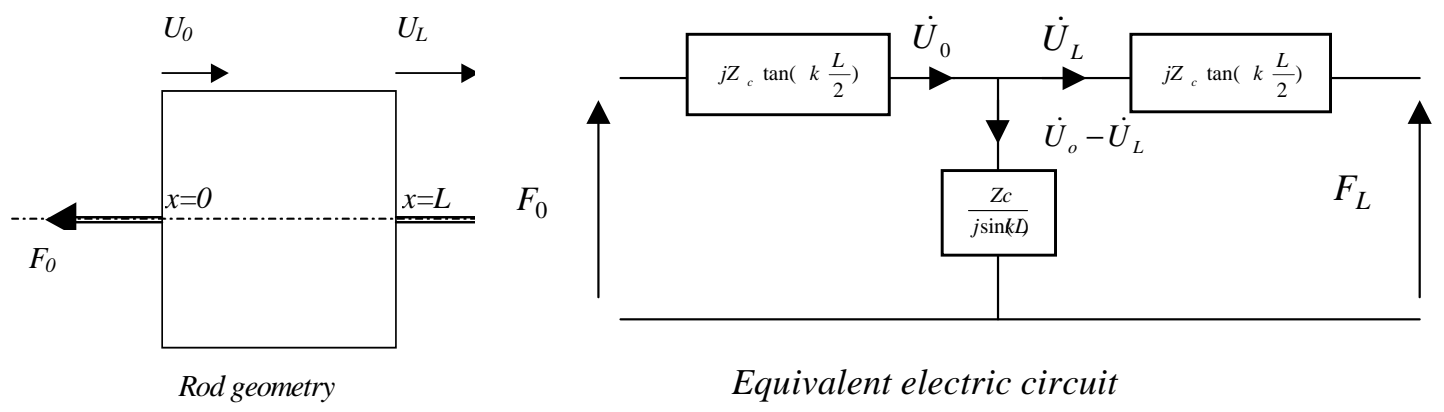

Figure $n^{\circ} 2$ : Non piezoelectric rod modeling

\section{Modeling by equivalent circuits of the stator}

Following this approach, the model of the stator of a rotating-mode motor has been developed, which, in this case, lends itself to the calculation of the characteristic bending magnitudes and hence the angular vibratory speed and moment at a section.

\section{Stator's equivalent diagram in flexion}

A flexural vibration system can be modeled with a transfer matrix which connects vibratory efforts and speeds in these two ends [6]. It is also possible to represent this matrix by an electric circuit. For that, an elementary cross-section of a beam of section $A$ and of moment of inertia $I$ is isolated in Fig. $n^{\circ} 3$.

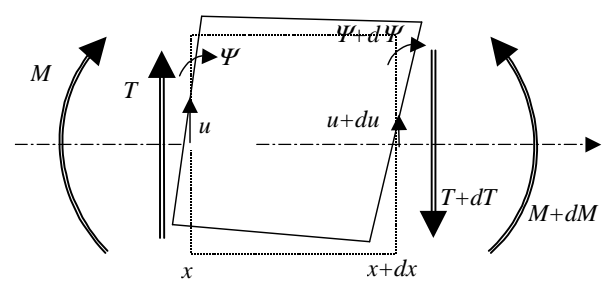

Figure $n^{\circ} 3$ : Elementary cross-section of a beam in flexion 
Displacement is orthogonal displacement $(u)$ or rotation angle ( $\Psi)$. Effort is shearing $(T)$ or moment $(M)$. By applying the fundamental principle of dynamics to this elementary volume, we get:

$$
\rho A \frac{\partial^{2} u}{\partial t^{2}}=-\frac{\partial T}{\partial x}
$$

$$
\rho I \frac{\partial^{2} \Psi}{\partial t^{2}}=\frac{\partial M}{\partial x}-T
$$

And

The equations of the resistance of the materials give:

$$
\frac{\partial \psi}{\partial x}=\frac{M}{c I}
$$

\section{And}

$$
\psi-\frac{T}{a_{T} A G}=\frac{\partial u}{\partial x}
$$

The beams studied here are relatively short: the moment of inertia $\operatorname{\rho Idx}\left(\partial^{2} \Psi / \partial t^{2}\right)$ of the section and the shearing effect $T /\left(a_{T} S G\right)$ will not be neglected [7]. We finally get:

$$
c I \frac{\partial^{4} u}{\partial x^{4}}+\frac{\rho^{2} I}{a G} \frac{\partial^{4} u}{\partial t^{4}}+\rho S \frac{\partial^{2} u}{\partial t^{2}}=\left(\rho I+\frac{c \rho I}{a G}\right) \frac{\partial^{4} u}{\partial t^{2} \partial x^{2}}
$$

For steady-state, sinusoidal excitation and vibration the following complex notation can be adopted: $u=U e^{j \omega t}$. The differential equation of propagation of the elastic wave then becomes:

$$
c I \frac{\partial^{4} U}{\partial x^{4}}+\omega^{2} \rho I\left(1+\frac{c}{a_{T} G}\right) \frac{\partial^{2} U}{\partial x^{2}}+\left(\omega^{4} \frac{\rho^{2} I}{a_{T} G}-\omega^{2} \rho S\right) U=0
$$

This has a solution of the form:

$$
U(x)=A \sin \left(k_{1} x\right)+B \cos \left(k_{1} x\right)+C \operatorname{sh}\left(k_{2} x\right)+D \operatorname{ch}\left(k_{2} x\right)
$$

with: $\quad k_{1}=\sqrt{\frac{\sqrt{\Delta}+\rho I\left(1+\frac{c}{a_{T} G}\right) \omega^{2}}{2 c I}} \quad$ and: $\quad k_{2}=\sqrt{\frac{\sqrt{\Delta}-\rho I\left(1+\frac{c}{a_{T} G}\right) \omega^{2}}{2 c I}}$

where:

$$
\Delta=\left(\rho I\left(1+\frac{c}{a_{T} G}\right) \omega^{2}\right)^{2}+4 c I \rho S \omega^{2}\left(1-\frac{\rho I}{a_{T} S G} \omega^{2}\right)
$$

The structure of the motor is excited by ceramics, which only excite moments of flexion. It can be supposed that for a length $L$ of non piezoelectric rod, only pure moments $M_{1}$ 
and $M_{2}$ are applied at the extreme sections $S_{1}$ and $S_{2}$ (shearing efforts $T_{1}$ and $T_{2}$ are then null).Starting from the general expression (7) of the orthogonal displacement $U$, the expression of the moments is:

$$
M(x)=\alpha_{M}\left(A \sin \left(k_{1} x\right)+B \cos \left(k_{1} x\right)\right)+\beta_{M}\left(C \operatorname{sh}\left(k_{2} x\right)+D \operatorname{ch}\left(k_{2} x\right)\right)
$$

with : $\alpha_{M}=c I\left(\frac{\rho \omega^{2}}{a_{T} G}-k_{1}^{2}\right) \quad$ and $: \quad \beta_{M}=c I\left(\frac{\rho \omega^{2}}{a_{T} G}+k_{2}^{2}\right)$

the expression of the angles is given by:

$$
\psi(x)=\alpha_{\psi}\left(A \cos \left(k_{1} x\right)-B \sin \left(k_{1} x\right)\right)+\beta_{\psi}\left(C \operatorname{ch}\left(k_{2} x\right)+D \operatorname{sh}\left(k_{2} x\right)\right)
$$

with : $\quad \alpha_{\psi}=\frac{k_{1}\left(\alpha_{M}+a_{T} S G\right)}{a_{T} S G-\rho I \omega^{2}} \quad$ and : $\beta_{\psi}=\frac{k_{2}\left(\beta_{M}+a_{T} S G\right)}{a_{T} S G-\rho I \omega^{2}}$

and the expression of the efforts is written :

$$
T(x)=\alpha_{T}\left(A \cos \left(k_{1} x\right)-B \sin \left(k_{1} x\right)\right)+\beta_{T}\left(C \operatorname{ch}\left(k_{2} x\right)+D \operatorname{sh}\left(k_{2} x\right)\right)
$$

with : $\alpha_{T}=a_{T} S G\left(\alpha_{\psi}-k_{1}\right) \quad$ and : $\quad \beta_{T}=a_{T} S G\left(\beta_{\psi}-k_{2}\right)$

By applying boundary conditions at the end sections $S_{1}$ and $S_{2}$ (shearing efforts $T_{1}$ and $T_{2}$ null) coefficients $A, B, C$ and $D$ can be determined as functions of angles $\psi_{1}$ and $\psi_{2}$. Once these coefficients are determined, the expression of the moments can be written:

$$
\begin{aligned}
& M_{1}=M\left(-\frac{L}{2}\right)= \\
& \text { (11) And } \quad M_{2}=M\left(+\frac{L}{2}\right)= \\
& \frac{\left(\psi_{1}+\psi_{2}\right)}{2\left(\alpha_{\psi} \beta_{T}-\beta_{\psi} \alpha_{T}\right)}\left(-\alpha_{M} \beta_{T} \tan \left(k_{1} L / 2\right)+\beta_{M} \alpha_{T} \tanh \left(k_{2} L / 2\right)\right) \\
& +\frac{\left(\psi_{1}-\psi_{2}\right)}{2\left(\alpha_{\psi} \beta_{T}-\beta_{\psi} \alpha_{T}\right)}\left(\alpha_{M} \beta_{T} \cot \operatorname{an}\left(k_{1} L / 2\right)+\beta_{M} \alpha_{T} \cot \operatorname{anh}\left(k_{2} L / 2\right)\right) \\
& -\frac{\left(\psi_{1}+\psi_{2}\right)}{2\left(\alpha_{\psi} \beta_{T}-\beta_{\psi} \alpha_{T}\right)}\left(-\alpha_{M} \beta_{T} \tan \left(k_{1} L / 2\right)+\beta_{M} \alpha_{T} \tanh \left(k_{2} L / 2\right)\right) \\
& +\frac{\left(\psi_{1}-\psi_{2}\right)}{2\left(\alpha_{\psi} \beta_{T}-\beta_{\psi} \alpha_{T}\right)}\left(\alpha_{M} \beta_{T} \cot \operatorname{an}\left(k_{1} L / 2\right)+\beta_{M} \alpha_{T} \cot \operatorname{anh}\left(k_{2} L / 2\right)\right)
\end{aligned}
$$

They can also be rewritten in the form of:

$$
M_{1}=M\left(-\frac{L}{2}\right)=\tilde{\alpha} \dot{\psi}_{1}+\tilde{\beta}\left(\dot{\psi}_{1}-\dot{\psi}_{2}\right)
$$

$$
M_{2}=M\left(+\frac{L}{2}\right)=-\tilde{\alpha} \dot{\psi}_{2}+\tilde{\beta}\left(\dot{\psi}_{1}-\dot{\psi}_{2}\right)
$$

And 
With : $\tilde{\alpha}=\frac{\alpha_{M} \beta_{T} \tan \left(k_{1} L / 2\right)-\beta_{M} \alpha_{T} \tanh \left(k_{2} L / 2\right)}{j \omega\left(\alpha_{\psi} \beta_{T}-\beta_{\psi} \alpha_{T}\right)}$ and $\tilde{\beta}=j \frac{\frac{\alpha_{M} \beta_{T}}{\sin \left(k_{1} L\right)}+\frac{\beta_{M} \alpha_{T}}{\sinh \left(k_{2} L\right)}}{\omega\left(\alpha_{\psi} \beta_{T}-\beta_{\psi} \alpha_{T}\right)}$

These equations can be put in the form of an electric equivalent circuit (Fig. $n^{\circ} 4$ ) as for a Langevin type transducer.

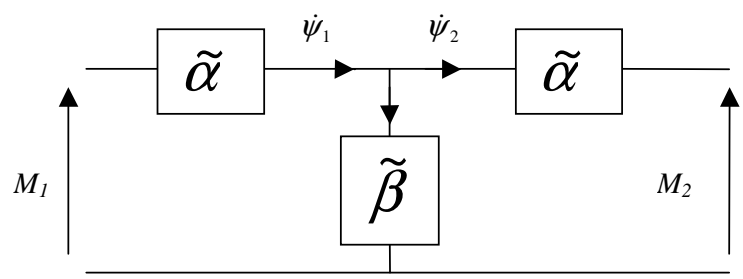

Figure $n^{\circ} 4$ : Electric form equivalent circuit

\section{Stator model validation and application}

This equivalent diagram represents the passive part (titanium) of the stator. The thicknesses of the active parts (PZT) are very small. The dynamics of the stator is thus rather well represented by this diagram. The engine functions on the first of resonance in free-free bending. This corresponds to null moments on ends of stator $\left(M_{1}=M_{2}=0\right)$. One can thus calculate the frequency of resonance when is $Z e q=\widetilde{\beta}+\tilde{\alpha} / 2$ null . For the geometry of stator of the figure $\mathrm{n}^{\circ} 2$, the calculated frequency is about $104 \mathrm{Khz}$ (value close to the $105 \mathrm{Khz}$ measured [1])

On the end surface of the stator, motion components in a cylindrical coordinate reference can be written as [2] :

$$
\left(\begin{array}{l}
U_{r} \\
U_{\theta} \\
U_{x}
\end{array}\right)=\left(\begin{array}{l}
U_{0} \cos (\omega t+\theta) \\
U_{0} \sin (\omega t+\theta) \\
-R \psi_{0} \cos (\omega t+\theta)
\end{array}\right)
$$

There is a travelling wave on the circumference of the stator. It is made up of two elliptic movements : a first, tangential and driving component, a second, radial and undesirable component. This undesirable component can be eliminated by inclining the 
contact zone (Fig. $\mathrm{n}^{\circ}$ ). The previous model is able to calculate this angle with geometrical parameters of the stator.

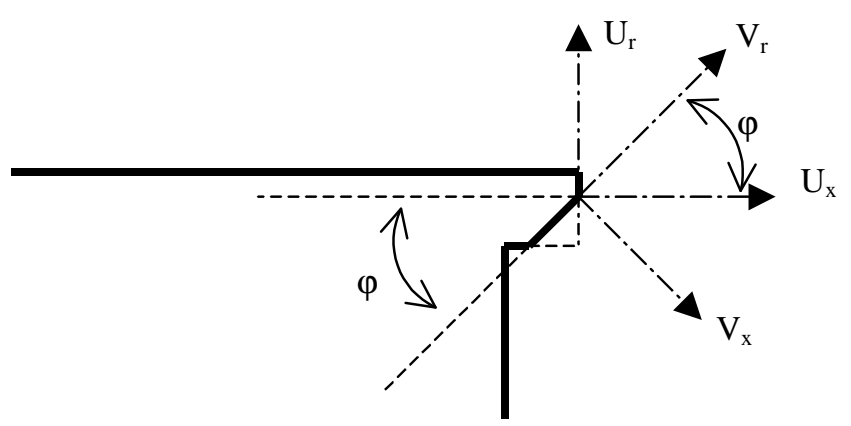

Figure $n^{\circ} 5$ : Contact zone geometry

To obtain a pure travelling wave without radial parasitic movement, the $V_{r}$ component of the radial component in a reference mark V, must be null. Angle $\varphi$ must check the following relation:

$$
\tan (\varphi)=\frac{R \psi_{0}}{U_{0}}
$$

To determine the value of $\varphi$, relation between $\psi_{0}$ and $U_{0}$ should be given. By taking again the equations described previously, one can show that:

$$
\dot{U}_{2}=\gamma \dot{\psi}_{2}, \text { with } \gamma=\frac{1}{2\left(\alpha_{\psi} \beta_{T}-\beta_{\psi} \alpha_{T}\right)}\left(\begin{array}{l}
\left.(2+\tilde{\alpha} / \tilde{\beta})\left(\beta_{T} \tan \left(k_{1} L / 2\right)-\alpha_{T} \tanh \left(k_{2} L / 2\right)\right)\right)- \\
(\tilde{\alpha} / \tilde{\beta})\left(\beta_{T} \cot \operatorname{an}\left(k_{1} L / 2\right)+\alpha_{T} \cot \operatorname{anh}\left(k_{2} L / 2\right)\right)
\end{array}\right)
$$

And thus :

$$
\tan (\varphi)=\frac{R_{e}}{\gamma}
$$

For the geometry of stator of the Fig. $\mathrm{n}^{\circ} 1$, the angle of inclination calculated is nearly $24.5^{\circ}$ (value close to the $25.5^{\circ}$ calculated by finite elements [1]).

\section{Piezoelectric effect modeling}


The ceramics used are a layer of PZT thin film. The poling direction of the PZT film is in the thickness direction and the bending vibration is generated by the length-extension effect. The electric field component $E$ can be assumed constant along the full length of the ceramic. Stress and strain are thus expressed by :

$$
\begin{aligned}
& S_{1}=s_{11}^{E} T_{1}+d_{31} E_{3} \\
& S_{1}(y)=(d \psi / d x) y \\
& E_{3}=-V / L
\end{aligned}
$$

Effort $T$ can be rewritten as :

$$
T_{1}=\frac{S_{1}}{s_{11}^{E}}+\frac{d_{31}}{s_{11}^{E}} \frac{V}{L}
$$

By integrating $T_{1} . y$ on the active surface of the ceramic, moment $M$ is deduced:

$$
M=\iint T_{1}(y) y d A=\frac{1}{s_{11}^{E}} \frac{d \psi}{d x} \iint y^{2} d A+\frac{d_{31}}{s_{11}^{E}} \frac{V}{L} \iint|y| d A
$$

which can equally be written in the form :

$$
M=\frac{I}{s_{11}^{E}} \frac{d \psi}{d x}+N V
$$

with:

$$
I=\iint y^{2} d A \quad \text { (22) } \quad \text { And } \quad N=\frac{d_{31}}{s_{11}^{E} L} \iint|y| d A
$$

In relation (21), an expression of the form $M=c I(d \psi / d x)$ can be found again, and the supplementary terms are equivalent to a moment $\Gamma=N V$. The electric equivalent circuit of stator (Fig. $\mathrm{n}^{\circ}$ 4) can be completed by a transformer which accounts for the electromechanical conversion which takes place at the level of the ceramic. The equivalent electric diagram of the stator is given Fig. $\mathrm{n}^{\circ} 6$ with $C_{0}$ the electric capacity of the ceramic. 


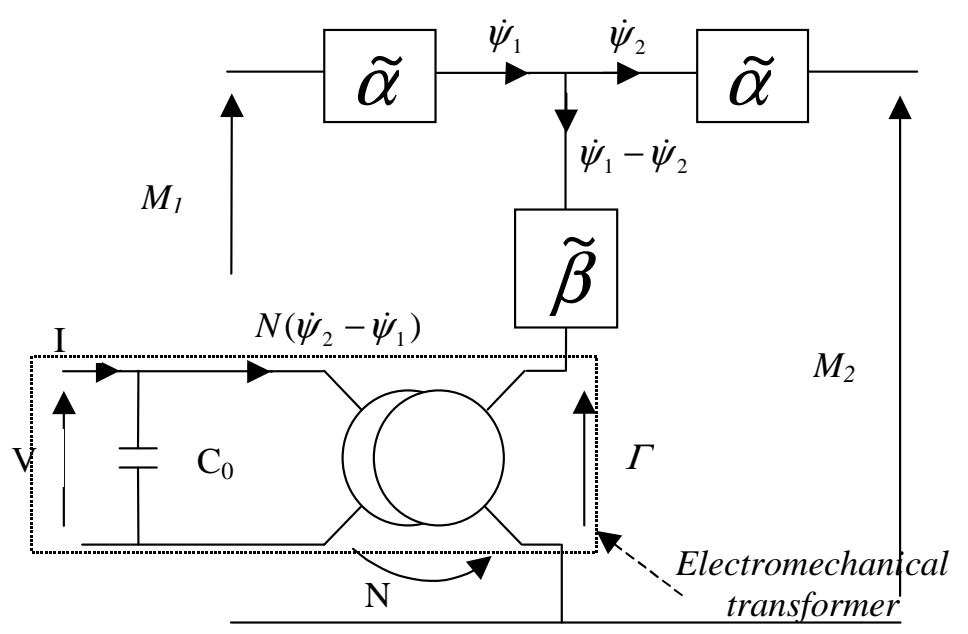

Figure $n^{\circ} 6$ : Equivalent electric diagram of micromotor stator

\section{Modeling of the stator/rotor contact}

To obtain the complete characteristics of the motor, it is necessary to add to the stator model, which describes the electromechanical power conversion, an analytical modeling of rotor/stator interaction. This stage has already been carried out for travelling wave actuators [8] [9].

\section{Zone of contact}

The vibrating stator is assumed to be equivalent to a portion of a cylinder and the rotor to a plane surface. Thus the rotor/stator contact is equivalent to a cylinder/plane contact of length $2 a$ (Fig. $\mathrm{n}^{\circ} 7$ ). Hertz's theory provides the length of contact and the distribution of pressure $p$. 


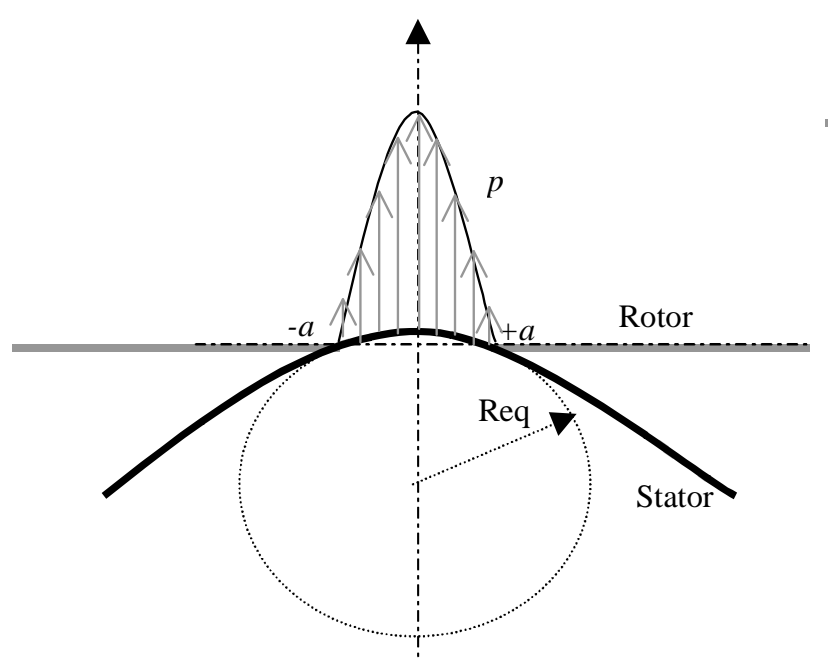

Distribution of pressure

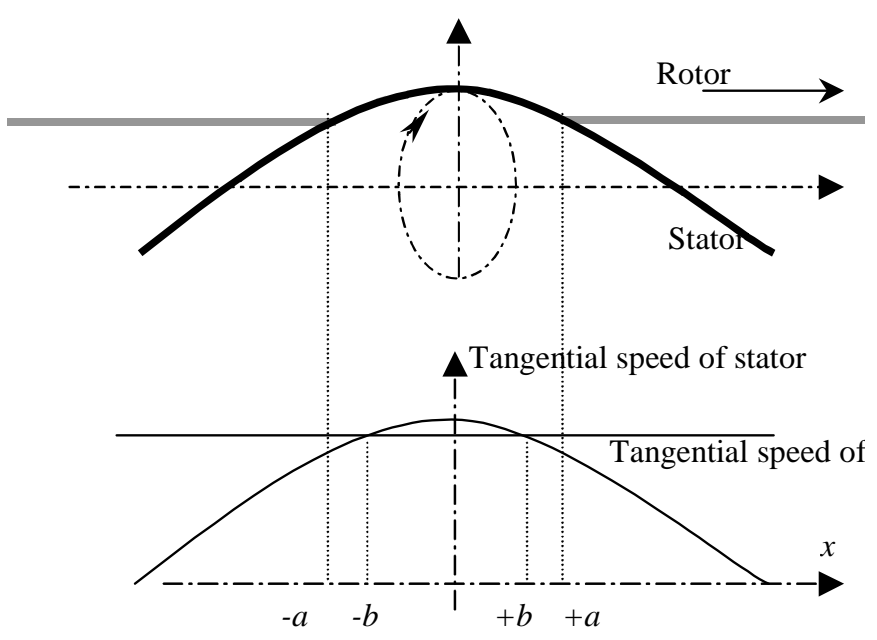

Distribution of tangential speeds

Figure $n^{\circ} 7$ : Contact Stator/Rotor

Let $x$ be the position on the external perimeter of the stator. The travelling wave deformation $y$ has for formula at $\mathrm{t}=0$ :

$$
y=R \psi_{0} \cos (\theta)=R \psi_{0} \cos (x / R)
$$

The radius of the equivalent cylinder $R_{e q}$ takes then the expression:

$$
R_{e q}=1 / \frac{\partial^{2} y}{\partial x^{2}}=\frac{R}{\psi_{0}}
$$

The length of contact takes as value:

$$
a=2\left(\frac{L_{n} R_{e q}}{\pi E^{*}}\right)^{1 / 2}
$$

with :

$L_{n}=\frac{F_{\text {pres }}}{c}$, the linear load ;

$\frac{1}{E^{*}}=\frac{1-\gamma_{\text {stator }}^{2}}{E_{\text {stator }}}+\frac{1-\gamma_{\text {rotor }}^{2}}{E_{\text {rotor }}}$, the equivalent elasticity constant.

The distribution of pressure $p$ is given by:

$$
p=P_{0}\left(1-\left(\frac{x}{a}\right)^{2}\right)^{1 / 2} \text { with } P_{0}=\frac{2 L_{n}}{\pi a}
$$

Calculation of the torque/speed curve for a given vibratory speed 
The rotor speed is deduced from the tangential part $U_{\theta}$ of elliptic movement:

$$
v=\dot{U}_{\theta}=U_{0} \omega \cos (x / R)
$$

In Fig. $\mathrm{n}^{\circ} 7$, co-ordinate $b$ corresponds to the point for which the local speed of the stator is equal at the tangential speed $\mathrm{V}_{\mathrm{r}}$ of the rotor :

$$
V_{r}=\dot{U}_{\theta}=U_{0} \omega \cos (b / R) \text { and } b=R \cdot \cos ^{-1}\left(V_{r} / U_{0} \omega\right)
$$

The efforts transmitted to the rotor depend on relative speed :

- For $v>V_{r}$ or $-\mathrm{b}<\mathrm{x}<+\mathrm{b}$ : positive ;

- For $v<V_{r}$ or $-\mathrm{a}<\mathrm{x}<-\mathrm{b}$ ou $+\mathrm{b}<\mathrm{x}<+\mathrm{a}$ : negative.

By taking a law of friction of the type $d F=\mu \cdot p \cdot s g\left(v-V_{r}\right) d S$, torque $C$ is calculated by:

$$
\begin{gathered}
C=2 \mu R\left(\int_{0}^{b} p(x) c d x-\int_{b}^{a} p(x) c d x\right)=2 \mu c R P_{0}\left(\int_{0}^{b} \sqrt{1-(x / a)^{2}} d x-\int_{b}^{a} \sqrt{1-(x / a)^{2}} d x\right) \\
C=2 \mu a c R P_{0}\left(\arcsin \left(\frac{b}{a}\right)+\frac{b}{a} \sqrt{1-\left(\frac{b}{a}\right)^{2}}-\frac{\pi}{4}\right)
\end{gathered}
$$

And for low speeds $(b \geq a)$, it takes the value:

$$
C_{\max }=\frac{\pi}{2} \mu a c R P_{0}=\mu F_{\text {pres }} R
$$

Considering these expressions, the torque/speed characteristic is given by Fig. $n^{\circ} 8$.

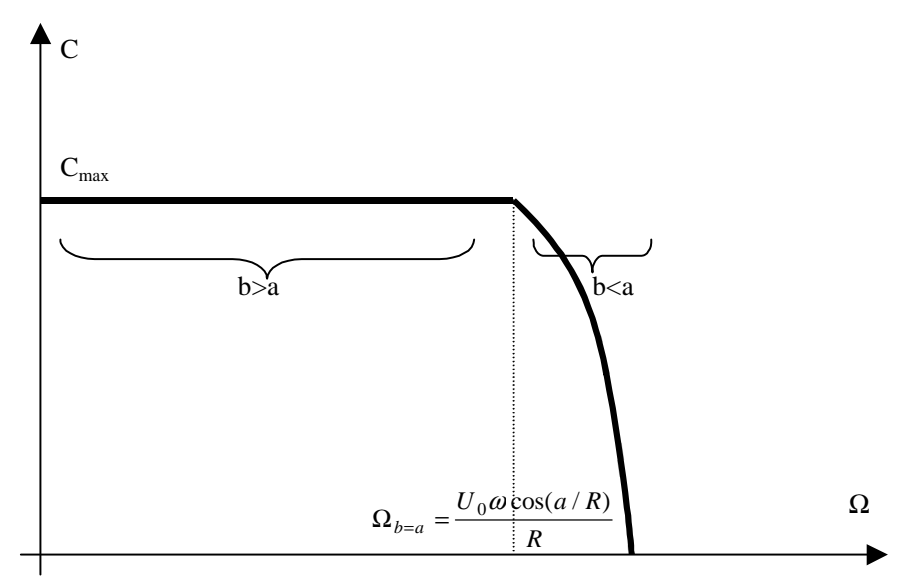

Figure $n^{\circ} 8:$ Torque/speed characteristic

\section{Expression of the mechano/mechanic conversion in the equivalent circuits}


For the points corresponding to the $b>a$ part of the characteristic (Figure 21.), the total power $P_{\theta}$ developed in the contact for the tangential movement can be written in the following form :

$$
P_{\theta}=2 \mu \int_{0}^{a} p(x) \cdot c \cdot v(x) d x=2 \mu c U_{0} \omega P_{0} \int_{0}^{a} \sqrt{1-\left(\frac{x}{a}\right)^{2}} \cos \left(\frac{x}{R}\right) d x
$$

If $\sqrt{1-\left(\frac{x}{a}\right)^{2}}$ is approximated by $\cos \left(\frac{\pi x}{2 a}\right), P_{\theta}$ becomes:

$$
\begin{aligned}
& P_{\theta}=2 \mu c U_{0} \omega P_{0} \int_{0}^{a} \cos \left(\frac{\pi x}{2 a}\right) \cos \left(\frac{x}{R}\right) d x, \\
& P_{\theta}=\mu c U_{0} \omega P_{0} \cos \left(\frac{a}{R}\right) \frac{\pi a}{\left(\frac{\pi}{2}\right)^{2}-\left(\frac{a}{R}\right)^{2}} .
\end{aligned}
$$

Moreover, another expression of $P_{\theta}$ is:

$$
P_{\theta}=P_{\text {operte }}+P_{\text {meca }} \text { with } P_{\text {meca }}=C_{\max } \Omega
$$

In equivalent circuits, the power $P_{\theta}$ could be calculated by:

$$
P_{\theta}=2 \frac{1}{2} \operatorname{Re}\left[M_{2} \dot{\psi}_{2}^{*}\right]=\operatorname{Re}\left[M_{2} \dot{\psi}_{2}^{*}\right]
$$

This expression can be rewritten according to (35), and to :

$$
\operatorname{Re}\left[M_{2} \dot{U}_{2}^{*}\right]=\operatorname{Re}\left[\not M_{2} \dot{\psi}_{2}^{*}\right]=\not P
$$

Then:

$$
P=\frac{\operatorname{Re}\left[M_{2} \dot{U}_{2}^{*}\right]}{\gamma}
$$

As $\dot{U}_{2}, \dot{\psi}_{2}$ and $M_{2}$ are assumed to be co- phasal, the final expression of $M_{2}$ is :

$$
M_{2}=\frac{\not P}{U_{0} \omega}=\mu c P_{0} \cos \left(\frac{a}{R}\right) \frac{\pi a}{\left(\frac{\pi}{2}\right)^{2}-\left(\frac{a}{R}\right)^{2}}
$$

In the same way for the radial movement, the power $P_{r}$ developed can be written : 


$$
\begin{aligned}
& P_{r}=2 \mu c U_{0} \omega P_{0} \int_{0}^{a} \cos \left(\frac{\pi x}{2 a}\right) \sin \left(\frac{x}{R}\right) d x \\
& P_{r}=\mu c U_{0} \omega P_{0} 2 a \frac{\frac{a}{R}-\frac{\pi}{2} \sin \left(\frac{a}{R}\right)}{\left(\frac{a}{R}\right)^{2}-\left(\frac{\pi}{2}\right)^{2}}
\end{aligned}
$$

As for power $P_{\theta}$, this power correspond to a tension $M_{2}$ given by expression :

$$
M_{2}=\mu c \gamma P_{0} 2 a \frac{\frac{a}{R}-\frac{\pi}{2} \sin \left(\frac{a}{R}\right)}{\left(\frac{a}{R}\right)^{2}-\left(\frac{\pi}{2}\right)^{2}}
$$

The equivalent circuit (Fig. $\mathrm{n}^{\circ}$ ) of the motor can thus be supplemented by adding :

A resistance $\mathrm{R}$ to take account of the mechanical losses within the stator (this resistance can be replaced by the use of complex elastic constant [15]) ;

- A voltage $E_{\theta}$ to represent the power developed by tangential vibratory movement (Eq. (50));

- A voltage $E_{r}$ to represent the power developed by tangential radial movement (Eq. (52)).

\section{Numerical implementation of the model}

Let us take the case of a micro motor made up of :

- A stator transducer (Fig. $\left.\mathrm{n}^{\circ} 1\right)$;

- Two rotors hold against the stator transducer at the top and the bottom by a spring.

The equivalent circuit of the motor is as Fig. $n^{\circ} 9$. 


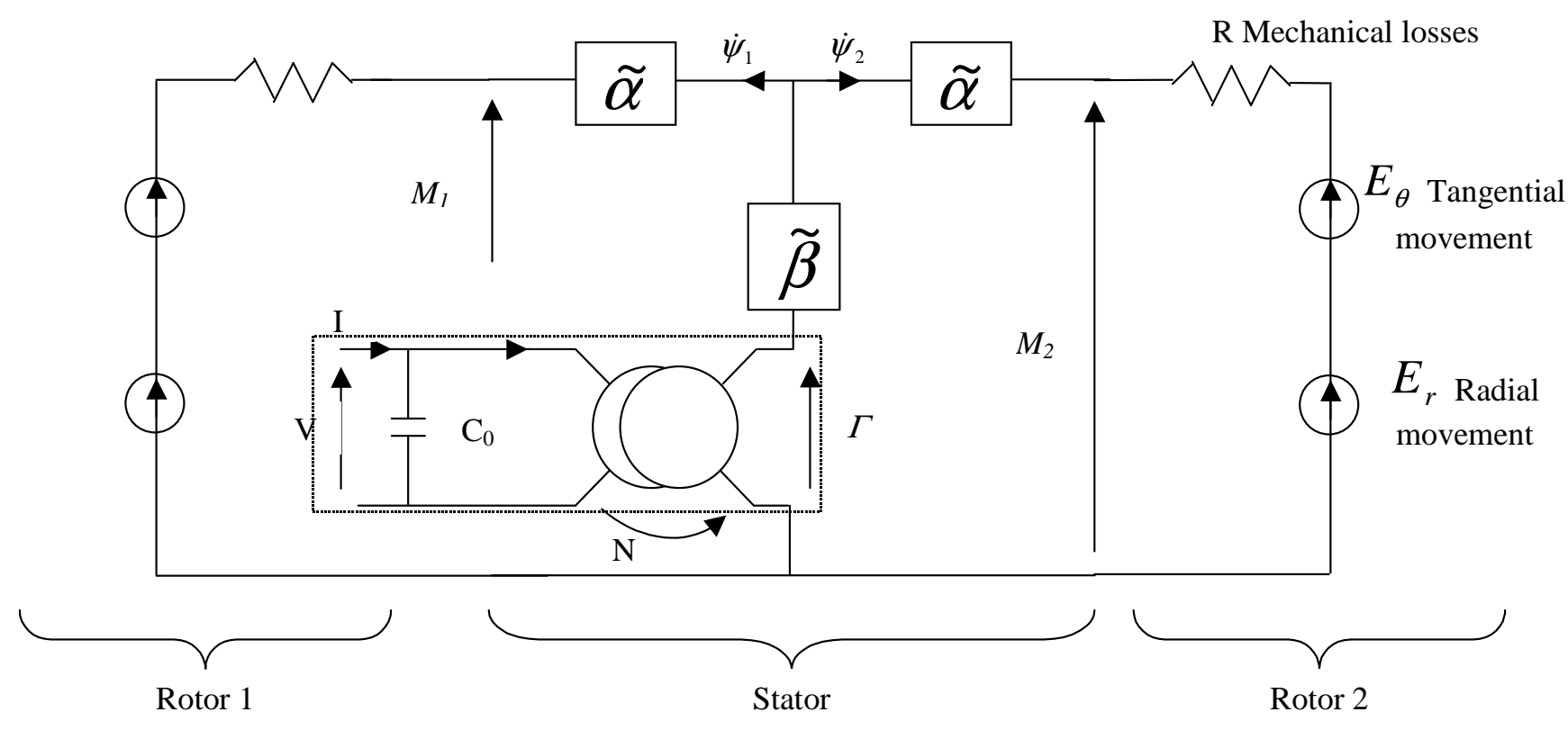

Figure $n^{\circ} 9$ : Equivalent electric diagram of micromotor

Near frequency resonance, the dynamic part of the circuit can be represented by a RLC equivalent circuit (Fig. $\mathrm{n}^{\circ}$ 10).

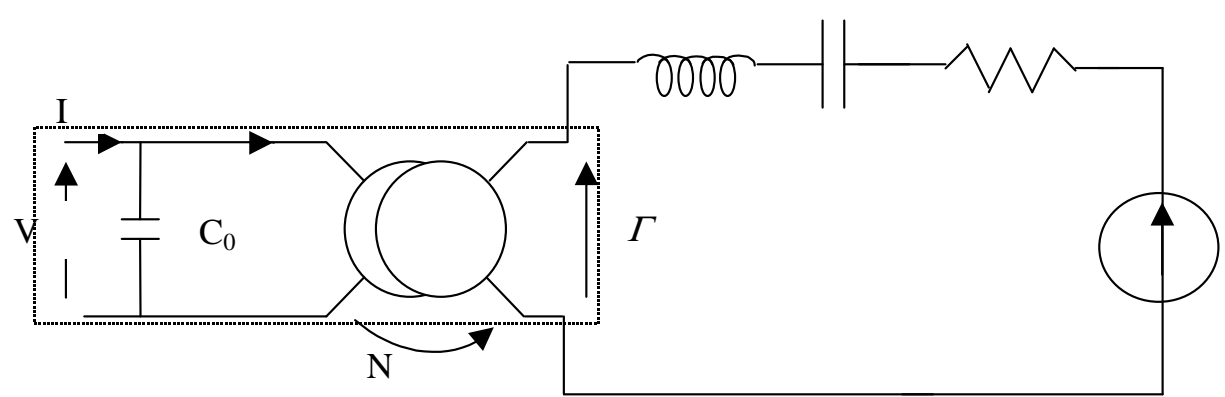

Figure $n^{\circ} 10$ : Equivalent RLC electric diagram of micromotor

The electromechanical characteristics of this motor can be obtained : No load admittance of the stator, torque/speed curve, the supply voltage. An example of results is presented in fig. $\mathrm{n}^{\circ} 11$ (No load admittance, Contact pressure, Torque/Speed curve with supply voltage). 

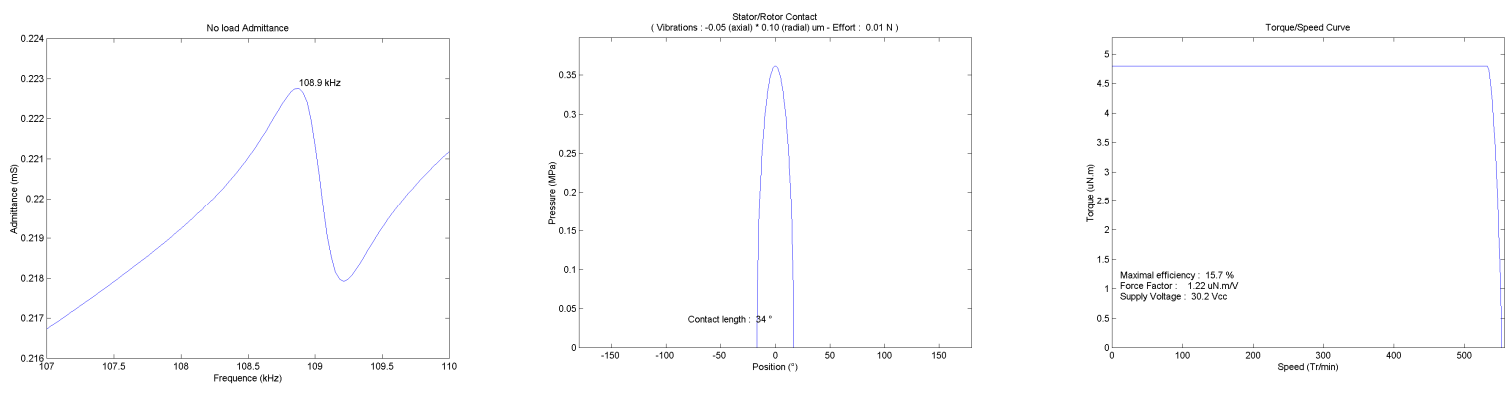

Figure $n^{\circ} 11$ : Electromechanical caracteristics

\section{Conclusion}

This article has presented a global model for cylindrical piezoelectric micromotor; it takes into account both electromechanical conversion in the stator and mechano-mechanical conversion between stator and rotor. The motor stator is represented here in a form very similar to a traditional Mason circuit. The differences occur in the particular configurations of movement, namely flexural instead of longitudinal vibrations. In the equivalent circuits, contact between rotor and stator is represented by voltages which are functions of vibratory speed. Useful results for design are obtained such as torque/speed curve, no load admittance, supply voltage, stress and amplitude of vibrations. Good agreements between model and numerical or experimental results are observed (on resonance frequency for example). This modeling is simple to implement and would also lend itself to optimisation by analytical methods [10] because of the relatively small amount of computation required. 


\section{References}

[1] T. Morita et al., Design of a cylindrical ultrasonic micromotor to obtain mechanical output, Jpn. J. Appl. Phys., Vol. 35 (1996), pp. 3251-3254

[2] Pin Lu et al., A kinematic analysis of cylindrical ultrasonic micromotors, Sensors and Actuators A 87 (2001) 194-197

[3] T. Sashida , T. Kenjo, An introduction to ultrasonic motors, Clarendon Press, OXFORD, 1993.

[4] S. Ueha, Y. Tomikawa, Ultrasonic Motors, Oxford Science Publication, 1993

[5] T. Ikeda, Fundamentals of Piezoelectricity, Oxford Science Publications.

[6] G. Zhou, The performance and design of ultrasonic vibration system for flexural mode, Ultrasonics 38 (2000), Elsevier Science, pp. 979-984

[7] S. Timoshenko, Résistance des matériaux, Dunod.

[8] Minotti P. et al., Moteur piezo-électrique à onde progressive : I. modélisation de la conversion d'énergie mécanique à l'interface stator/rotor, Journal de Physique III., 1996, vol. $6, \mathrm{n}^{\circ} 10$, p. $1315-1337$

[9] J.F. Rouchon, Ph. Kapsa, The elastic contact area between a sinusoidal indentor and a layered solid : application to calculation of ultrasonic motors performances, 29 oct.2 Nov 1995, YOKOHAMA, Japon.

[10] Messine F., Nogarede B., Lagouanelle J.-L., Optimal design of electromechanical actuators : a new method based on global optimization, IEEE transactions on magnetics, 1998, vol. 34, n$^{\circ} 1$, pp. 299-308 


\section{Notations}

\begin{tabular}{ll}
$\Psi$ & Rotational angle \\
$\omega$ & Frequency \\
$\rho$ & Density \\
$\gamma$ & Poisson constant \\
$\mu$ & Friction constant \\
$\varepsilon^{S}$ & Dielectric constant for constant S \\
$A$ & Section area \\
$a$ & Half length of contact (Hertz theory) \\
$a_{T}$ & Timoshenko's coefficient \\
$C$ & Elastic stiffness \\
$C_{0}$ & Clamped capacity \\
$C^{D}$ & Elastic stiffness for constant-D \\
$D$ & Electric displacement component along axe $x{ }^{\prime} O x$ \\
$E$ & Electric field component along axe $x$ 'Ox \\
$e$ & Piezoelectric constant \\
$E_{\theta}$ & Equivalent voltage for tangential movement \\
$E_{r}$ & Equivalent voltage for radiall movement \\
$F_{p r e s}$ & Effort on stator \\
$G$ & Coulomb modulus \\
$H$ & Piezoelectric constant \\
$I$ & Moment of inertia \\
$I$ & Current \\
$k$ & Wave number \\
$k_{33}, k_{31}$ & Coupling factor \\
$L$ & Length of rod \\
$L_{n}$ & Linear load (Hertz theory) \\
$M$ & Bending moment \\
$N$ & Force factor \\
$p$ & Contact pressure \\
$P_{\theta}$ & Power of the tangential movement \\
$P_{0}$ & Maximum pressure of contact (Hertz theory) \\
$P_{r}$ & Power of the radial movement \\
$R$ & Cylinder radius \\
$R_{e q}$ & Radius of equivalent cylinder (Hertz theory) \\
$S$ & Strain \\
$T$ & Shear force \\
$U$ & Displacement \\
$V$ & Supply voltage \\
& \\
\hline &
\end{tabular}

